\title{
3 \\ Some statistical context for analysis of CDEP
}

\author{
Boyd Hunter
}

\section{Introduction}

This volume includes four case studies of communities that have been affected by the reforms to the Community Development Employment Projects (CDEP) outlined in the previous chapters. The first three case studies are based in very remote parts of Australia where the scheme was a prominent feature of the Indigenous labour market between its inception in 1977 and closure in 2015. Those sites are based in the Anangu Pitjantjatjara, ${ }^{1}$ Anmatjere and Maningrida census regions. The other case study site is based on the far south coast of NSW. This chapter will provide rudimentary information on CDEP scheme employment for those areas, as well as some broader statistical context on the CDEP scheme derived from administrative, survey and census data.

Chapter 2 comprehensively documented the significant changes in the CDEP scheme rules and administration over the last decade; however, this chapter provides statistical analysis to provide some insights into likely impacts of these reforms. Looming large among these changes is

1 Note that 'Anangu Pitjantjatjara' is the statistical region as defined by the Australian Bureau of Statistics, but this corresponds in practice to the Anangu Pitjantjatjara Yankunytjatjara Lands. 
the fact that CDEP jobs have disappeared since 2006. From its height in 2002-03 when it had over 35,000 participants, the CDEP scheme declined slowly to around 32,800 around the time of the 2006 census, after which it was soon cut to less than a third of its former size. At the time of the 2011 census, administrative records indicated that only 10,700 participants remained on the scheme (Gray et al. 2014). While CDEP continued in remote areas until June 2015 (albeit with such reduced numbers), the analysis here focuses on the intercensal period between 2006 and 2011, the most recent year for which there are available data from statistical collections.

The substantial policy changes relating to CDEP have been disproportionately felt in certain areas. As noted above, the scheme was eliminated in most non-remote areas in 2007, but this chapter will illustrate that between 2006 and 2011 some remote areas experienced greater reduction in CDEP participation than others. The extent to which changes in CDEP affected local communities during that intercensal period should be greatest in the areas that lost most CDEP participants.

There has been considerable research into 'Coombs' bastard child' since its inception in 1977 (Sanders 2012). Ironically, the zenith of understanding about the composition of the CDEP workforce was probably reached just after the scheme entered its declining years (or what Sanders called its 'lingering old age'). It is well documented that CDEP was historically associated with working part-time, while participation tended to be disproportionately male and focus on employing younger people (Altman et al. 2000). On average, CDEP participants had a higher income than people who were unemployed or not in the labour force (NILF), but a substantially lower income than people employed in mainstream jobs outside of CDEP (i.e. the non-CDEP employed).

Hunter and Gray (2013) build on these facts and confirm that CDEP participants experienced significantly better socioeconomic outcomes than the unemployed in a wide range of issues (including crime, health, financial stress, and community security). CDEP participation was also strongly associated with the maintenance of language and culture as well as an ongoing connection to traditional lands.

One particularly salient finding in Hunter and Gray (2013) is that the main characteristics of remote CDEP jobs did not change between 1994 and 2008. That is, if a person was employed in a CDEP job during 
both 1994 and 2008, they could have expected to receive similar employment outcomes for themselves and for their local communities. Given that CDEP schemes were closed in most non-remote areas in 2007, these changes would have had a significant effect on regions like the far south coast of NSW (see Chapter 4). The size of any such effect will depend on the number of jobs lost as a proportion of the resident population.

Of course, former CDEP scheme workers may find other jobs, may become unemployed, may leave the labour force or may even leave the local area. This chapter will provide some bounds on the likely effect of the loss of 35,000 CDEP jobs by estimating the marginal effects of former workers entering various labour force states using Hunter and Gray (2013).

Commonly, case studies are conducted in areas where researchers have existing connections and social links that allow the research to be undertaken. This is clearly a sensible strategy designed to maximise the amount of usable information collected in a qualitative study. There is always a question as to how representative the case studies are of the circumstances they seek to characterise. However, qualitative research does not usually attempt to generalise its findings in terms of the representativeness of the information provided, but rather appeals to the depth or quality of information attained from particular individuals or case studies. This chapter also attempts to situate the remote case studies in terms of location and some broad census characteristics as well as limited information provided from administrative sources.

The next section introduces the administrative data on CDEP employment after 1997 to illustrate the magnitude of the loss of CDEP scheme work. The third section revisits some salient findings from Hunter and Gray (2013) and reflects on the consequences of the decline and demise of CDEP since 2006. The fourth section uses some little-known data from the first longitudinal analysis of Indigenous jobseekers to reflect on the transition of CDEP participants and Indigenous unemployed into mainstream employment. The chapter then attempts to estimate the likely effects of the demise of the CDEP scheme using available evidence. The CDEP communities analysed in the case studies are then introduced through a mixture of some rather messy administrative data for CDEP schemes and analyses of some basic census data for remote Indigenous Areas and the Indigenous Location 
for Wallaga Lake within the far south coast of NSW case study (i.e. the most disaggregated Australian Bureau of Statistics (ABS) geographic levels designed specifically to analyse Indigenous statistics). The final section briefly reflects on this statistical context and the implications for the analysis in the rest of this book.

\section{Charting the decline in the number of participants in the CDEP scheme}

In order to provide some statistical context for the recent changes to CDEP, this section analyses administrative data back to 1997. Fig. 3.1 below is an extension of the chart presented in Hunter and Gray (2013) so that it covers the entire period up to the 2011 census. The first thing to note about Fig. 3.1 is that there was a disproportionate number of males employed in the scheme. Some of this gender bias is due to the fact that males are more likely to participate in the labour market (Hunter \& Daly 2013). However, this cannot be the sole explanation as males have been at times twice as likely to be employed in CDEP whereas the overall labour force participation rate of Indigenous males is not twice as high as that of Indigenous females (Gray et al. 2014).

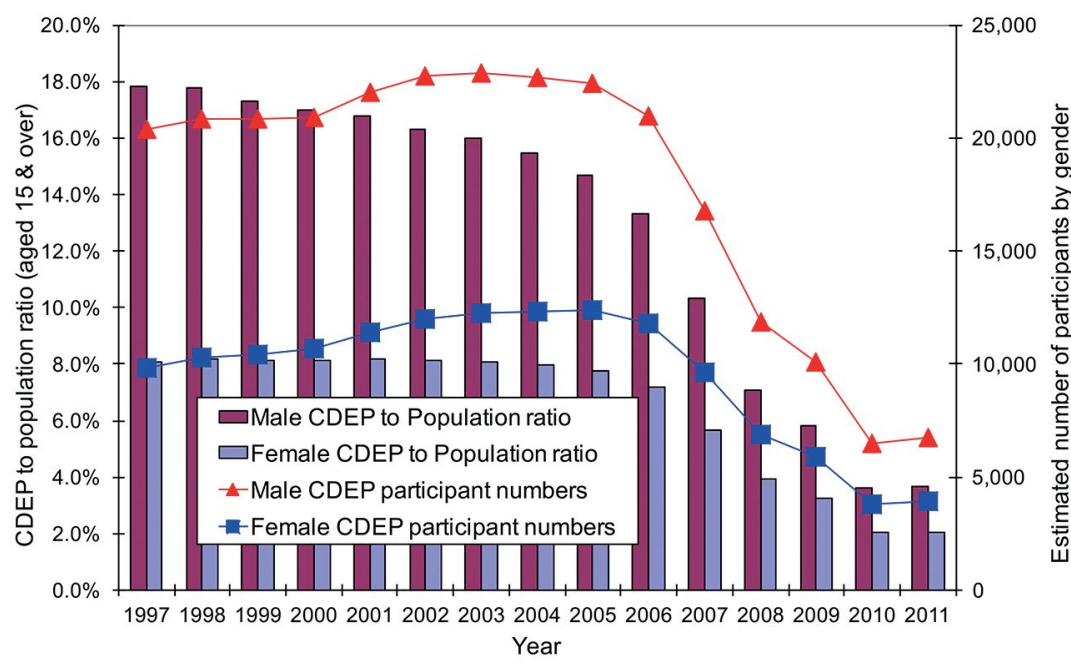

Fig. 3.1 CDEP employment/population ratio, Indigenous males and females aged 15 and over, 1997-2011

Note: There is some CDEP data available before 1997 but it is difficult to compare this information with the most recent data.

Source: Hunter and Gray (2013). The 2011 estimates derived in Gray, Hunter and Howlett (2013). 
The information about CDEP participation has become somewhat patchy since 2011 , but the limited administrative data that are available show that the downward trend continued unabated. The number of people employed as 'grandfathered' CDEP participants (those who had commenced in the scheme prior to July 2009 and who still received CDEP wages) continued to decline up to 2015 when these transitional arrangements were phased out. In answer to a question on notice to the Senate Finance and Public Administration Legislation Committee by Senator Jan McLucas, the Department of the Prime Minister and Cabinet indicated that, as at 16 March 2015, the total number of recipients grandfathered under the CDEP wages scheme was 2,221. The next section will provide a rough estimate of the loss of around 35,000 CDEP jobs using the analysis provided in Hunter and Gray (2013). However, in order to estimate the effect of the decline of CDEP employment one needs to make an assumption about what happens to the people who are no longer employed in the CDEP scheme.

It is not unreasonable to assume that the vast majority of former CDEPemployed have moved to welfare payments akin to what is commonly called Newstart (or simply unemployment benefits). Forrest (2014: Chapter 4) claimed that there were about 35,000 jobseekers registered in the Remote Jobs and Communities Program (RJCP) - the scheme that had largely replaced CDEP by that time - with only about 3,000 of that number registered as receiving income through the grandfathered CDEP wages arrangement. The remaining jobseekers were in receipt of other forms of income support (e.g. Newstart Allowance and Youth Allowance). It is a remarkable coincidence that the number of people registered in the RJCP was roughly equivalent to the total number of CDEP scheme jobs administered at the height of the scheme in 2002-03. In view of the population growth that has occurred since 2002, the positions in the scheme would have had to expand to maintain the situation that existed 13 years ago. I will consider three possibilities about the movement of former CDEP workers in the next section - that they moved into non-CDEP scheme employment, became unemployed, or exited the labour force.

While the administrative data are relatively consistent, it is important to reflect on the inadequacies of various statistical data sets on Indigenous labour force status, especially with respect to people employed through the CDEP scheme. According to ABS (2013a), and consistent with the numbers presented in Fig. 3.1, there was a total 
decline of almost 22,000 CDEP participants across Australia between the previous two censuses collected in 2006 and 2011 (i.e. derived by adding the change in male and female participation). However, the total number of people in CDEP scheme employment identified in the census was much lower. The 2006 census counted 14,497 employed in CDEP and the 2011 census counted 5,005 in the same category. Given that there should be a one-to-one correspondence between CDEP employment and participation, this represents a decline of 9,492 CDEP-employed in the census - less than half of the actual decline in CDEP participation measured in administrative data between 2006 and 2011. There are two major reasons for the under-reporting of CDEP in census collections: CDEP information was only being collected by an interviewer in some remote areas (entirely overlooking participant numbers in regional and urban areas); and there is considerable uncertainty about how remote CDEP participants may have reported their CDEP and employment status in the census.

Labour force comparisons between the 2006 and 2011 censuses may also be affected by the recent changes to CDEP. To the extent that some remote CDEP participants were recorded in the census in 2006 and were no longer CDEP participants in 2011, they may be recorded as either unemployed or not in the labour force in the most recent census depending on the respondents' understanding of their circumstances. Similarly, those still participating in CDEP in 2011 may not have understood or reported themselves as such if they were no longer in receipt of CDEP wages. The ABS were certainly aware of such issues. Even though CDEP information for 2011 was collected and processed by the ABS in the same way it was for the 2006 census, the ABS (2013a) recommend care should be taken when comparing 2006 and 2011 census CDEP counts because the recent reforms 'may have an impact on the numbers of people reporting that they are CDEP participants'.

There appear to be some subtle differences in statements in the ABS monthly Labour Force Survey (LFS) about CDEP (ABS 2011a, 2012a, 2013b). In ABS (2011a), participants who joined after July 2009 received unemployment benefits instead of CDEP wages, and were considered by the ABS to be undertaking unpaid work in a similar manner to those in the Work for the Dole scheme. The basis of this decision was a presumption that the relationship between employer/ 
employee changed with the CDEP policy reforms. In ABS (2012a), the situation was clarified (with a different arrangement of words that avoided any analogy with the Work for the Dole scheme):

In remote communities, participants who joined CDEP prior to July 2009 will continue receiving wages ... under the new Remote Jobs and Communities Program (RJCP) and continue to be classified as employed. New participants will receive income support benefits instead of CDEP wages, and are therefore not considered to be in an employer/employee relationship and will not be classed as employed.

Another more recent ABS statement indicates that, in order to accommodate the introduction of RJCP (in July 2013), the shorter version of the LFS questionnaire was modified slightly (ABS 2013b):

to differentiate between those working under CDEP (wages) and those working under RJCP/CDEP (income support payments). Those employed under CDEP (wages) will be classified as employed because they have an employer/employee relationship, while those under RJCP/ CDEP (income support payments) will be classified as unemployed or not in the labour force, depending on whether or not they are looking for work.

It is difficult not to sympathise with the ABS who have obviously struggled to make statistical sense of labour force concepts in a time of complex policy reform. However, it also must be incredibly difficult for the participants and the interviewers to interpret and classify people as having CDEP (wages) or CDEP (income support payments). Perhaps the most telling admission on the relevant issues was in ABS (2012a):

[T] here are practical difficulties with applying these standard LFS concepts and definitions in Indigenous communities, particularly in remote regions. When interviewers encounter significant cultural, language or operational difficulties in remote communities, a 'short form' is used to collect the minimum data required to derive basic labour force characteristics, and this does not always capture the complex issues that are involved in defining CDEP participation.

Since a person in the RJCP was expected to work for their welfare payment, the experience of some former CDEP participants may not have been that different under the RJCP. Alternatively, CDEP participants who were still in receipt of wages in 2011 may have 
been aware of the policy shift, but may not have believed that their experience was any different to that of the RJCP participants who they knew to be classified as unemployed.

This section has demonstrated that it was very difficult to statistically measure the labour force status of CDEP participants and former participants using surveys and even censuses. Following ABS (2011b), I will not attempt to directly compare the CDEP statistics in the 2006 and 2011 censuses. Nonetheless, it is clear that by July 2015 the 35,000 former CDEP positions no longer existed.

It is important to explore the implications of the loss of these positions, but it is necessary to make some assumptions about what has happened to the former CDEP participants in terms of labour force status. While RJCP (or, at the time of writing, the Community Development Programme (CDP)) participants nominally 'work for the dole', they are arguably closer to being unemployed than CDEP scheme workers in terms of the experience of participants (see Chapter 2). There is some anecdotal evidence that many CDP providers are having trouble providing work-like activities for participants. In the context of the broader policy debate, there have been doubts cast about the value of the mainstream Work for the Dole, which unlike CDEP does not seem to offer different outcomes compared to other unemployed (Borland \& Tseng 2011). In attempting to estimate the effect of the loss of CDEP positions, the next section assumes that CDP participation is equivalent to being unemployed for the person in question.

Given that Forrest (2014) reports that there were 35,000 participants in the new scheme, it might be reasonable to assume that many of the 35,000 former CDEP positions have resulted in the participants becoming unemployed. However, it is the explicit intention of the policy reform that former CDEP participants should find mainstream employment. It is difficult to gauge from available data exactly what has happened, but the following section reports some unique data from the 1990s to provide a foundation for the estimation of the impact of the demise of the CDEP scheme. 


\section{Evidence on transitions from CDEP from the Indigenous Job Seeker Survey}

In order to estimate the extent to which CDEP participants find mainstream jobs, it is necessary to collect longitudinal data. The Australian Census Longitudinal Dataset (ACLD) links data for almost 15,000 Indigenous people identified in the 2006 and 2011 censuses. This new longitudinal data set allows for a representative analysis of some labour force transitions for Indigenous Australians (ABS 2013c). Unfortunately, this analysis cannot document the effect of changes in the CDEP scheme as the ACLD does not include information on it. Therefore, in order to estimate labour force transitions of former CDEP participants one has to consider other non-representative longitudinal data.

In the 1990s, the only large-scale longitudinal data on Indigenous Australians was the Indigenous Job Seeker Survey (IJSS). Gray and Hunter (2005) use the IJSS to show that Indigenous unemployed were around half as likely to move to employment over a 15-month period as were the non-Indigenous unemployed. However, the IJSS also allows analysts to distinguish between CDEP participation, unemployment and non-CDEP employment and hence it provides potentially unique insights.

Hunter, Gray and Jones (2000) provide a detailed introduction to the survey methodology. The survey was conducted using face-to-face interviewing, predominantly involving Indigenous interviewers. Interviews were conducted by Roy Morgan Research who worked collaboratively with Indigenous organisations in each region. One important feature of the IJSS was that jobseekers were eligible for inclusion if they resided within reasonable travelling distance from a mainstream labour market, with the aim of excluding jobseekers who would be limited to CDEP scheme employment. Postcode areas that fell more than $100 \mathrm{~km}$ from the city or town centre were excluded to limit interviewer travel costs.

The IJSS is not entirely satisfactory data to estimate what might happen to former CDEP participants as many of the 35,000 former CDEP participants lived in areas that were more than $100 \mathrm{~km}$ away from a town. Another limitation for this evidence is that it is based on 
relatively few observations ( 65 males and 25 females). Nonetheless, the IJSS provided some evidence that CDEP participation was associated with some transitions into mainstream employment if opportunities for such employment existed (a condition that is implicitly assumed by the designers of the policy). Despite the limitations of the IJSS data, it arguably provides an optimistic estimate of the labour market possibilities of former participants that can be contrasted to the more pessimistic scenario that none of the former participants find employment.

Table 3.1 reports disaggregated labour force transitions for Indigenous males and females over a 15-month period between 1996 and 1997 (Gray \& Hunter 2005). In general, CDEP scheme participants had slightly better transitions to full-time and part-time employment than Indigenous persons identified in the IJSS as unemployed. This is consistent with the claim that CDEP prepared participants by providing experience that is useful in mainstream jobs.

The transitions from CDEP into employment are much closer to the average transitions into employment for the Australian unemployed (Gray \& Hunter 2005: Table 4) than Indigenous unemployed measured in the IJSS (Table 3.1). While this provides an optimistic assessment of the possible transitions for former CDEP participants, it is consistent with what is observed for non-Indigenous unemployed (at least, as measured in the second half of the 1990s).

In order to operationalise these data, I average the approximate transitions by constructing a weighted average of the male and female data. In the IJSS about 31 per cent of former CDEP participants found mainstream jobs (i.e. including both full-time and part-time jobs), while around 29 per cent stayed in CDEP and just over 24 per cent became unemployed jobseekers. The residual 16 per cent moved out of the workforce altogether and were then classified as not in the labour force (NILF).

Clearly, most CDEP participants did not live close to urban areas, and even where they did the labour force outcomes in the IJSS might not eventuate (see Chapter 4). Nonetheless, while I acknowledge the limitations of these data, they provide some basis for an estimate of the optimistic scenario of what might happen to former CDEP participants. 


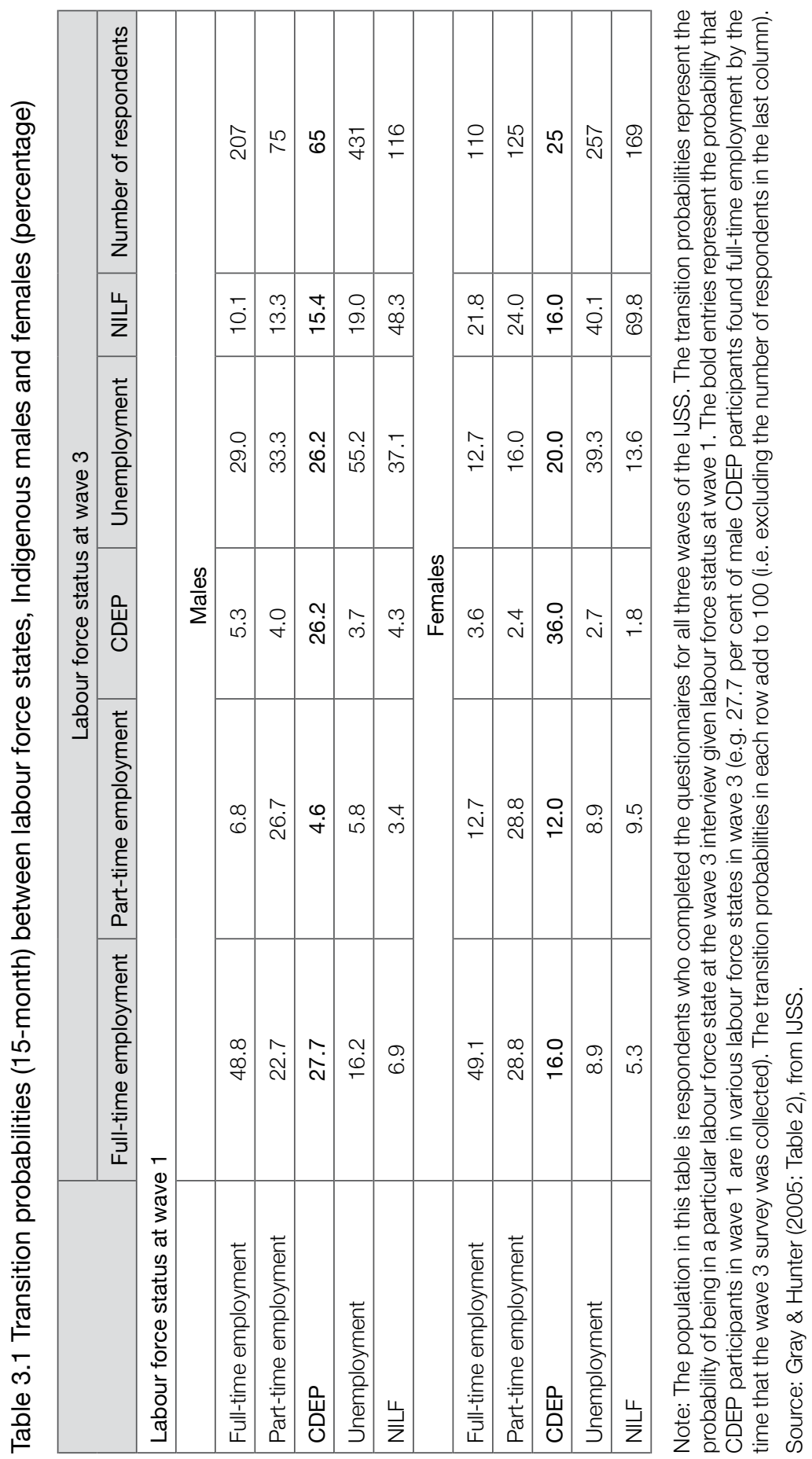




\section{Estimating the potential effect of the demise of CDEP}

While longitudinal data on labour force status is scarce for Indigenous Australians, there is a substantial amount of cross-sectional evidence available about outcomes for CDEP participants and other labour force states. Hunter and Gray (2013) described the nature of CDEP employment in 2008 and the extent to which it changed between 1994 and 2008. They concluded that CDEP work had remained largely unchanged over that period with virtually no change in the number of hours worked or the income of people employed through CDEP (adjusted to take into account changes in the consumer price index).

Other important evidence from the cross-sectional data presented in Hunter and Gray (2013) is that CDEP appeared to give some support for Indigenous language and customary practice by providing economic activity that allowed participants to live on or near their traditional country. However, the evidence that participation in CDEP improved community development through reducing discrimination or enhancing a sense of personal efficacy in important community issues is weak. Indeed, having a job is probably more important for enhancing the sense of personal efficacy in the community rather than whether or not one's job is associated with the CDEP scheme.

More important in the context of this volume, Hunter and Gray (2013) also compared a selection of economic outcomes of CDEP participants with those of Indigenous people who were non-CDEP employed, unemployed or NILF. While the incomes of CDEP participants had not increased substantially between 1994 and 2008, their incomes were higher than those of both the unemployed and NILF at both points in time. However, over this period the income of the non-CDEP employed increased rapidly and hence the incomes of CDEP participants fell relative to the incomes of the non-CDEP employed. There are several reasons for these findings. First, CDEP participants qualified for additional income above their income support entitlement in the form of a CDEP 'participant supplement'. In 2008, this was $\$ 20.80$ per fortnight. Second, historically, the income test applied to CDEP payments was more generous than the income test applied to income support payments (e.g. Parenting Payment, Newstart), and CDEP wages were not subject to the same 'taper' as unemployment benefits. 
(That is, CDEP participants could earn substantially more additional income over and above their base payment than social security recipients, without that base payment being reduced.) $)^{2}$

It is very difficult (or impossible) to identify the causal impacts of participation in CDEP on the well-being of participants compared with other Indigenous people. This is because we do not know what their well-being would have been were they not participating in the scheme (i.e. the counterfactual). The approach taken in this chapter is to compare the outcomes of CDEP participants with people in other labour force states.

Hunter and Gray (2013) estimate the association of labour force status (CDEP, non-CDEP employed, unemployed and NILF) with selected well-being measures using multivariate regression models. The regression models allow the associations between labour force status and well-being to be estimated while holding constant the effects of other variables that might impact upon well-being independent of labour force status. That analysis updates similar estimates by Hunter (2009) of the associations between labour force status and well-being using the 2002 National Aboriginal and Torres Strait Islander Social Survey (NATSISS). The only differences in the measures of well-being analysed here to those analysed by Hunter (2009) are that the earlier study examined substance use, which is not available from the 2008 NATSISS data; and Hunter and Gray (2013) include a measure of living in a low-income household - a measure not examined in the 2009 study.

Three main sets of outcomes are analysed in Hunter and Gray (2013) and reported in Table 3.2 below. The first set relates to crime and safety: whether respondents have been arrested, whether they live in a violent neighbourhood, and whether they have been a victim/ survivor of crime. The second set of variables comprises financial measures: whether respondents have experienced financial stress and have a low household income. The third variable relates to health: whether respondents have fair or poor health. Another outcome that was analysed in the Hunter and Gray regressions was whether

2 From July 2009 the rules changed so that while new CDEP participants could still work part-time (in addition to their CDEP commitments), their CDEP payment was reduced in line with the standard 'taper' for income support payments. However, it is not entirely clear how these rule changes were implemented in practice. 
a person was studying. ${ }^{3}$ However, it is not reported here as there was no difference in the probability of studying from either those who were employed through CDEP or those who were NILF.

Table 3.2 Marginal effect of CDEP and other labour force categories on selected social and economic outcomes, 2008

\begin{tabular}{|c|c|c|c|c|}
\hline & \multicolumn{3}{|c|}{$\begin{array}{c}\text { Marginal effect } \\
\text { (difference from unemployed) }\end{array}$} & \multirow[b]{2}{*}{$\begin{array}{l}\text { Base probability for } \\
\text { unemployed (\%) }\end{array}$} \\
\hline & $\begin{array}{l}\text { CDEP } \\
(\%)\end{array}$ & $\begin{array}{l}\text { Non-CDEP } \\
\text { employed (\%) }\end{array}$ & $\begin{array}{l}\text { NILF } \\
(\%)\end{array}$ & \\
\hline Arrested & $-5.8^{\star *}$ & $-13.1^{\star \star \star}$ & $-5.6^{\star \star \star}$ & 21.1 \\
\hline Violent neighbourhood & -3.7 & $-6.1^{\star \star \star}$ & $-7.2^{\star \star \star}$ & 40.0 \\
\hline Victim of crime & $-5.5^{\star}$ & $-6.9^{* *}$ & -2.3 & 29.0 \\
\hline Financial stress & $-6.3^{*}$ & $-25.1^{\star \star \star}$ & 1.0 & 59.5 \\
\hline Low household income & $-26.6^{\star \star \star}$ & $-56.0^{\star \star \star}$ & $-4.8^{*}$ & 65.5 \\
\hline Fair or poor health & $-6.8^{* \star}$ & $-12.0^{\star \star \star}$ & $8.5^{\star \star \star}$ & 25.0 \\
\hline
\end{tabular}

Note: The asterisks indicate statistically significant differences in the outcome variable for each labour force state compared to the unemployed. ${ }^{\star * \star}$ indicates a difference at 1 per cent level, ${ }^{* *}$ a difference at the 5 per cent level and * a difference at the 10 per cent level.

Source: Hunter and Gray (2013: Table 6).

There were statistically significant differences in the social and economic outcomes of CDEP participants compared to the unemployed and those NILF. The CDEP-employed were 5.8 percentage points less likely to have been arrested than the unemployed, 5.5 percentage points less likely to have been a victim of actual or threatened physical violence, 6.3 percentage points less likely to have experienced financial stress, 26.6 percentage points less likely to live in a low-income household and 6.8 percentage points less likely to report having fair or poor health status. While CDEP participants had better outcomes on a range of economic and social measures than the unemployed, CDEP participants had much worse outcomes than the non-CDEP employed for all of the social and economic outcomes analysed.

3 Disability was also included in Hunter and Gray (2013), but is not reported here because the disability rates are not significantly different for CDEP and unemployed in 2008. Also, it is difficult to maintain that it is an outcome of labour force status, as disabilities tend to be longterm health conditions. 
Although the data presented in this chapter are consistent with the hypothesis that CDEP participation had some small positive socioeconomic and health impacts, it could equally be the case that the slightly better outcomes for CDEP participants compared to the unemployed are because those who participate in CDEP have better outcomes prior to commencing on CDEP (i.e. there may be 'selection effects' on unobservable characteristics of individuals). While it is not possible to disentangle these alternative hypotheses using the available data, it is the case that the CDEP-employed have slightly better outcomes for most measures than the unemployed, and generally substantially worse outcomes than those for the non-CDEP employed. The estimates in Table 3.2 control for the main sociodemographic, geographic and educational factors measured in the survey.

In order to estimate the effect of the loss of 35,000 CDEP jobs, we need to make an assumption about the participants' effective labour force status after they leave the scheme. Table 3.3 is based on two scenarios: a realistic scenario based on what appears to be happening and an optimistic scenario based on labour force transitions described in the IJSS. The first scenario is based on the 35,000 former CDEP participants eventually all taking up the option of the new CDP scheme, which is ostensibly equivalent to the standard labour force category 'unemployment'. The second 'optimistic' scenario is that a substantial proportion of these former participants either secure mainstream employment or move out of the labour force altogether. One reason why it could be characterised as being excessively optimistic is that most remote labour markets are likely to have relatively few jobs available. This second scenario is based on the IJSS labour force transitions, which are the only Indigenous-specific longitudinal data that could be used. The eventual outcome may lie somewhere between the two scenarios, but probably closest to the realistic scenario. 
Table 3.3 Hypothetical simulations of the 'effect' of loss of 35,000 CDEP jobs

\begin{tabular}{|l|r|r|}
\hline & $\begin{array}{r}\text { Realistic scenario } \\
\text { (albeit pessimistic) }\end{array}$ & Optimistic scenario \\
\cline { 2 - 3 } & $\begin{array}{r}\text { CDEP participants } \\
\text { become unemployed }\end{array}$ & $\begin{array}{r}\text { CDEP participants experience } \\
\text { labour force transitions } \\
\text { consistent with IJSS }\end{array}$ \\
\hline Arrested & 2,030 & 295 \\
\hline Violent neighbourhood & 1,295 & 230 \\
\hline Victim of crime & 1,925 & 1,048 \\
\hline Financial stress & 2,205 & -462 \\
\hline Low household income & 9,310 & 2,965 \\
\hline Fair or poor health & 2,380 & 1,554 \\
\hline
\end{tabular}

Notes: The probability of each labour force state having a particular outcome is derived from Table 3.2. The estimated number of additional people experiencing the particular outcomes as a result of the loss of 35,000 CDEP jobs is calculated based on the respective scenarios.

Source: Prepared by the author.

Given that CDEP employment has been associated with positive outcomes, we should expect that converting those jobs into income support payments and unemployment will lead to considerable socioeconomic dislocation and stress. In all three domains represented in Table 3.3-interactions with the criminal justice system, income estimates and health estimates - at least 2,000 extra people are adversely affected in the conversion of those places into unemployment. The largest impact of the demise of CDEP appears to be increasing the number of people living in low-income households. The additional number of people living in such households represents over onequarter of the former participants (i.e. 27 per cent).

The optimistic scenario involves substantially less socioeconomic dislocation and stress. Indeed, the assumption that a substantial number of former participants find mainstream work could lead to a situation where there are actually fewer households experiencing financial stress. However, even this optimistic scenario is associated with substantially higher rates of arrest, violence and crime, more people living in low-income households and greater numbers of Indigenous people experiencing fair or poor health. Note that there is no contradiction between the estimated effect for financial stress and low-income households in that the substantially higher wages of those 
who are assumed to secure mainstream jobs are offset by the larger group who are assumed to be either classified as unemployed or leave the labour force altogether. Therefore, even in the most optimistic scenario, the demise of the CDEP scheme will have had substantial economic and social effects on the communities affected.

\section{Introducing the CDEP schemes analysed}

This section identifies and analyses organisations associated with CDEP schemes in the case study areas using data from the 2006 and 2011 censuses. During this period, changes to the scheme were profound in terms of the drop in the number of program participants and rule changes for both the program participants and the organisations providing the scheme. With respect to the organisations running the scheme, there was also considerable rationalisation around 2007, such that community-based schemes were now usually run at a more regionalised level. This regional model evolved out of the Department of Employment and Workplace Relations' contracting process, but presumably this decision was also made in anticipation of cost savings on relatively fixed administration expenses and other 'economies of scale' (Martin 2001).

Table 3.4 reports the names of the case study CDEP organisations in 2006 and 2011 and their numbers of participants, based on administrative data provided by the Department of Families, Housing, Community Services and Indigenous Affairs (FaHCSIA).

The first case study focuses on Anangu Pitjantjatjara communities where there were 10 discrete schemes participating in 2006. By 2011, those schemes were amalgamated and delivered by one organisation (Bungala Aboriginal Corporation) rather than the separate local community councils. In 2011, Bungala was also delivering CDEP to additional regions, such that interpreting the administrative data becomes difficult - that is, a judgement needs to be made about the proportion of Bungala's participants who were in the Anangu Pitjantjatjara region. Bungala advised that the number of participants in 2011 covered by the 10 communities in those original 2006 schemes was 400. Therefore the drop in the overall number of CDEP participants in Anangu Pitjantjatjara communities between 2006 and 2011 was almost 30 per cent (i.e. a drop from 568 to 400 ). 
The Anmatjere case study focuses on the scheme run by the Anmatjere Community Government Council at the time of the 2006 census. By 2011, that scheme had been amalgamated with two other schemes, Yuendumu Community Government Council and the Yuelamu Community schemes, to form a larger CDEP organisation run by the Central Desert Shire Council. If the number of participants in the three 2006 schemes are aggregated, there are 272 people involved, but by 2011 the Central Desert Shire scheme had 316. This is a modest increase of 15 per cent, especially when one takes into account the likely population growth in the area. If the 2011 data are assumed to be based on geographic patterns from the 2006 administrative data, the estimated increase in number of participants in the area covered by Anmatjere Community Government Council CDEP in 2006 is around 16 per cent (i.e. from 120 to 139). ${ }^{4}$ Of course, even this aggregate change in CDEP participation could mask some localised changes in CDEP participation.

The Maningrida case study is relatively straightforward in terms of the administrative data in that its CDEP scheme was run by the Bawinanga Aboriginal Corporation in both census years. Between 2006 and 2011, the number of participants fell by 23 per cent from 564 to 437 . In terms of sheer numbers this is a noteworthy drop, especially after the likely growth in the resident population is taken into account.

The administrative data for the far south coast of NSW case study are somewhat problematic, in that the number of CDEP participants appears to have changed substantially around August 2006 (i.e. the official census date for that year). From 1 July 2006, Wallaga Lake CDEP Inc., which had historically delivered CDEP in the region, was dissolved and its CDEP activities taken over by OPEN Inc. When Wallaga Lake CDEP Inc. closed it had around 80 participants. ${ }^{5}$ The numbers dropped substantially when the program was transferred to OPEN Inc., with administrative data recording 41 participants (see further discussion of this change in Chapter 4).

4 That is, the three communities with 2006 schemes were treated more or less equally in terms of the allocation of participants. Therefore the 316 places in the Central Desert Shire scheme in 2011 are distributed in proportion to the number of participants observed in the three 2006 organisations (i.e. $(120 / 272)$ x $316=139)$.

5 Pers. comm. Richard Barcham, former manager at Wallaga Lake CDEP Inc. 
3. SOME STATISTICAL CONTEXT FOR ANALYSIS OF CDEP

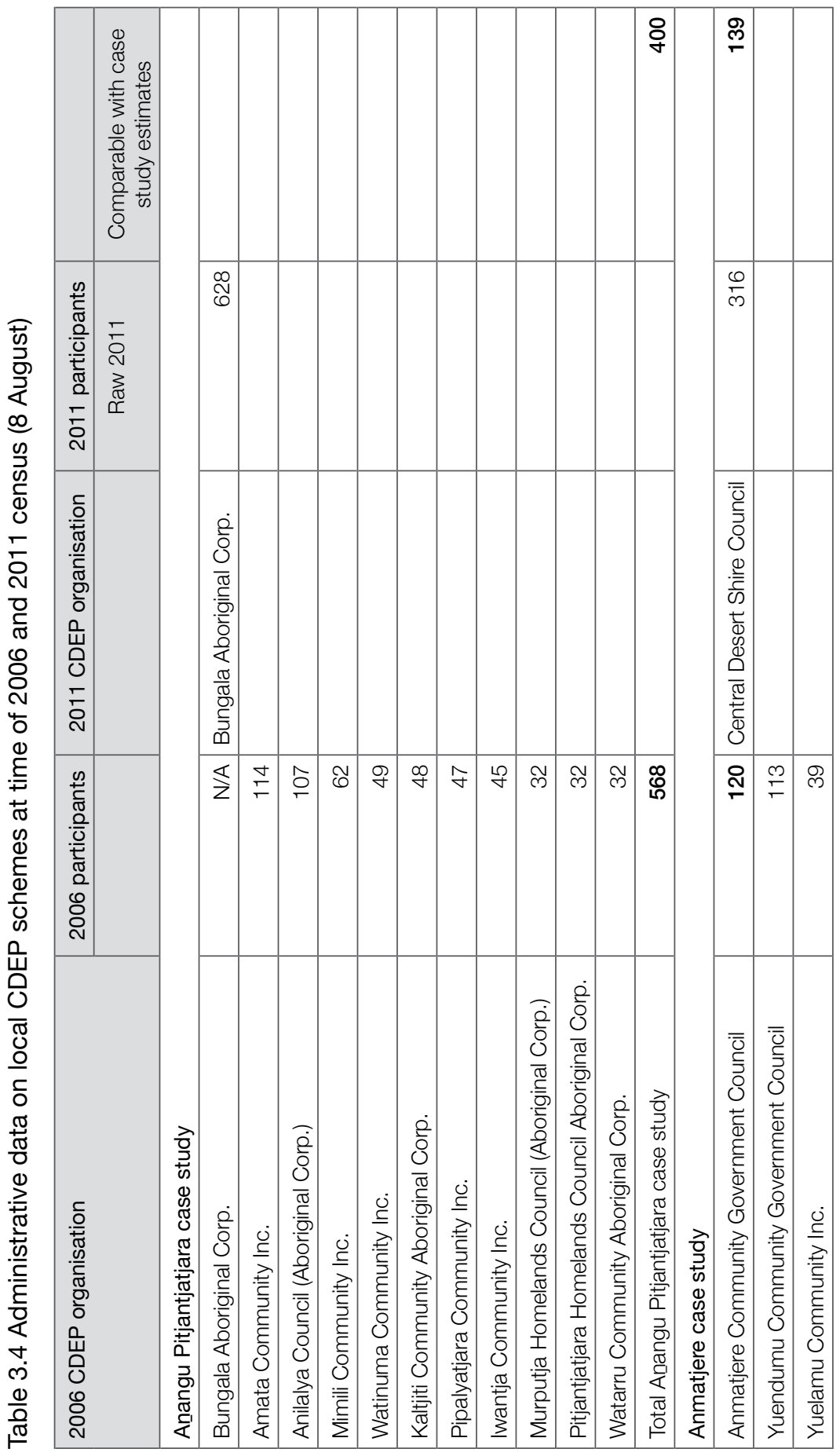


BETTER THAN WELFARE?

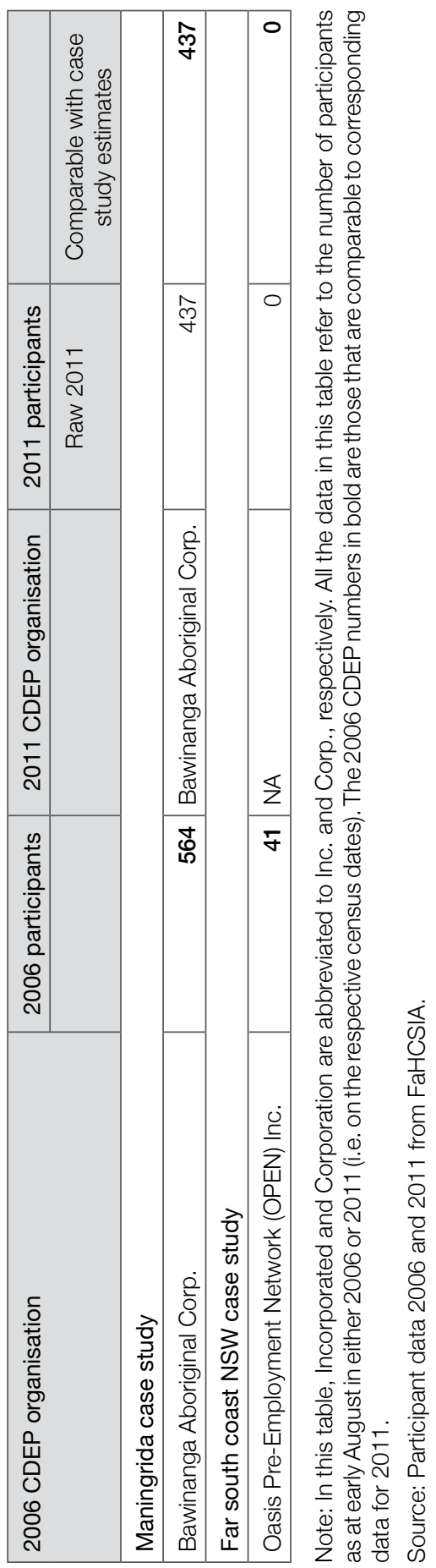


Whichever number is emphasised for the far south coast of NSW, it is clear that no CDEP scheme operated there in 2011. Hence, the effect of CDEP reforms in 2007 on this regional area is likely to be more pronounced in 2011 than the effect in remote areas because there was in effect an almost 100 per cent loss of employment and services provided by former 2006 participants. The Wallaga Lake CDEP scheme had included participants from the broader region, especially Bega and Eden. However, given data limitations, this chapter focuses on the Wallaga Lake area itself. Wallaga Lake Koori Village is a relatively small and discrete community in the far south coast region so we would expect, all else being equal, that the effect of the loss of CDEP was relatively pronounced there.

\section{Remote CDEP case studies}

The administrative data for CDEP provide only limited insights into the effect of CDEP's decline in the case study areas examined in this volume. With the possible exception of Bawinanga, it is difficult to know how much the geographic scope of the organisation changed as a result of the reorganisation of the scheme from around 2007. Accordingly, I now turn to the census counts for 2006 and 2011 to describe what happened to the local populations in the case study areas relative to other remote areas. All 119 remote Indigenous Areas (IAREs) in Australia are included in the following analysis and I use the geographic boundaries for the areas used at the time of the 2011 census. Geographic concordance data is used to ensure that the 2006 census results reported refer to the statistics for the people who lived in those boundaries in 2006.

One advantage of using census data is to construct broad comparable results. The following analysis takes into account the extent of CDEP participation in 2006, well before the major changes to the scheme (especially the regionalisation of providers from 2007 and the shift away from CDEP wages from 2009). Table 3.5 reports the basic census counts of the working-age population (aged between 15 and 64) for the IAREs that contain the three remote case studies. In most of these areas, the census also records information on the number of CDEPemployed. Note that in 11 remote IAREs, no CDEP-employed were recorded in the census. This could indicate one of two things: first, 
and most probably, there was no CDEP scheme operating in the IARE, and second that CDEP-employed were not identified because that census information was not collected by interviewers in those areas.

It is somewhat reassuring that the counts of CDEP-employed people in the census are not too different from the number of participants recorded by the organisations administering the scheme (reported in Table 3.4). If we express the counts of CDEP-employed in the 2006 census as a percentage of participants recorded in FaHCSIA databases at a similar time (6 August 2006), then over 60 per cent of participants in the respective remote case study areas were counted in the 2006 census. Sometimes the coverage of CDEP participants is even higher, with almost nine-tenths of Anmatjere Community Government Council CDEP participants being counted in the 2006 census ( 88 per cent). This is remarkably close given that the counts do not take into account the significant tendency for census data to under-enumerate the Indigenous population (ABS 2012b). We can be reasonably confident that the coverage of CDEP participants is reasonably good in the three remote case study areas, at least in 2006.

In order to construct valid analysis of the case study areas with broadly comparable areas, I have divided the IAREs with some CDEP employment into those areas with less than 20 per cent of the working-age population employed in the scheme and those areas with 20 per cent or more of their population so employed. All three case studies fall in the latter category where CDEP employment is relatively prominent among the potentially economically active population. This allows us to make some rudimentary comparisons of the outcomes in the case study areas with other remote areas depending on the intensity of their initial participation in the CDEP scheme. Before examining the facts, we expect the case studies to be most like those IAREs with relatively high participation in CDEP schemes. Conversely, we expect the case studies to be least like the IAREs without any CDEP employment in 2006. That is, if an area had a substantial labour market then there would be less pressure to set up a CDEP scheme in the first place. The comparator groups for the case studies are listed in the first three columns of numbers. The CDEP comparator groups are evenly split into the less intense CDEP scheme areas where the effect of CDEP is likely to be relatively weak and the areas where the effect of CDEP is more likely to be pronounced. 


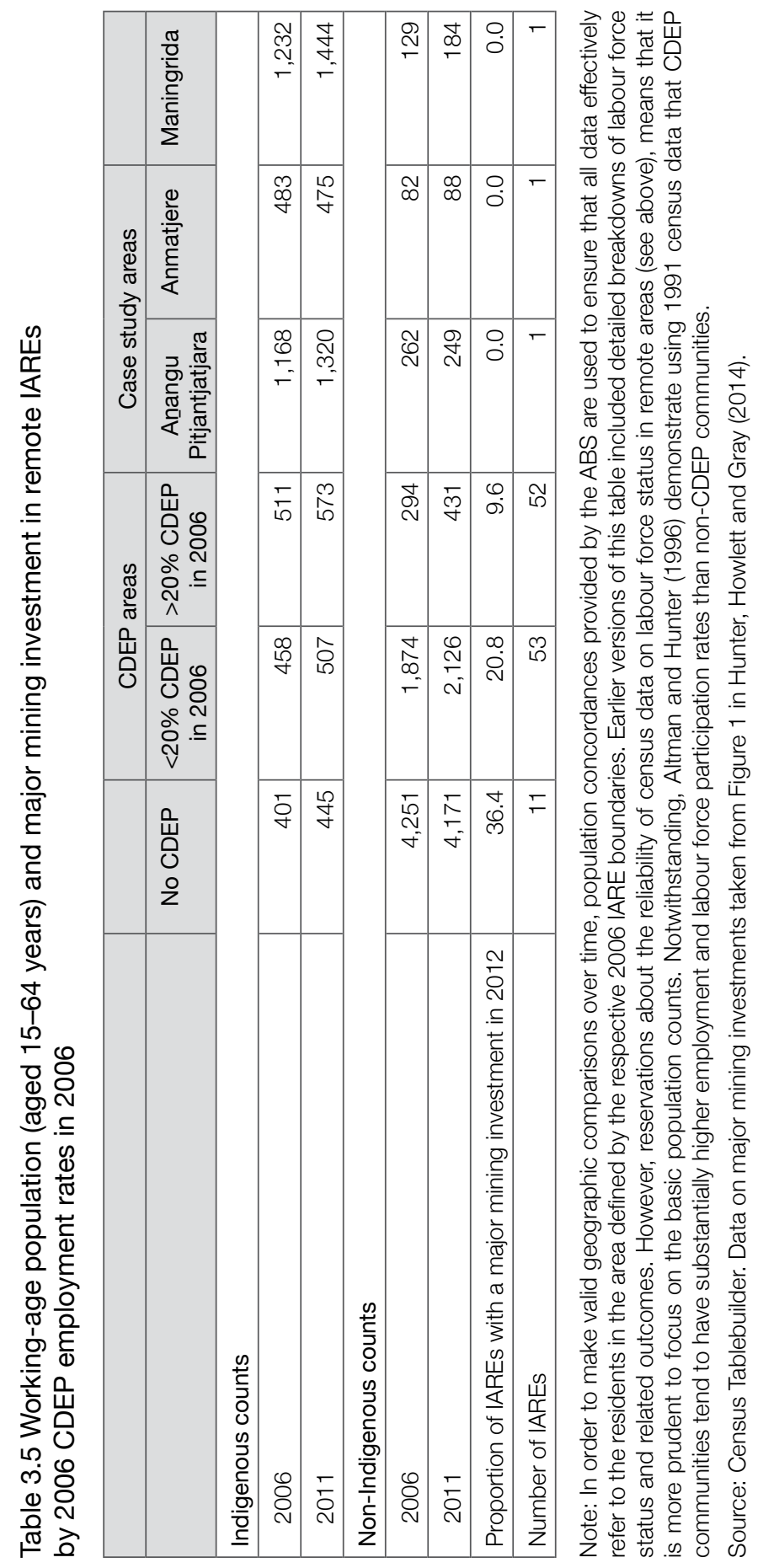


Table 3.5 is also useful for identifying distinctive features of the case study IAREs, which may make them atypical communities. Anangu Pitjantjatjara and Maningrida both have relatively large Indigenous populations with well in excess of 1,100 Indigenous working-aged residents in 2006. However, the IARE that includes the Anmatjere case study has similar counts of Indigenous residents to that reported in our three groups of comparator IAREs (listed in the first three columns). All three case study regions are strongly Indigenous and all have relatively few non-Indigenous residents in the working-age range. In terms of the comparator groups, only the 'CDEP intense areas' have a relatively small non-Indigenous presence.

When the 2006 census counts of CDEP-employed are expressed as a proportion of the working-age population (Fig. 3.2), the Anangu Pitjantjatjara case study was the most CDEP intense case study, with well over a third of the relevant population recorded as working in the scheme ( 35.3 per cent). All else being equal we would expect that any effect of CDEP reforms would be felt most keenly in this IARE. Given that the average proportion of the remote Indigenous working-age population employed in CDEP in the 2006 Census is around 24 per cent (i.e. excluding areas without any CDEP scheme), the participation in CDEP is reasonably typical in both Anmatjere and Maningrida (21.7 per cent and 28.1 per cent respectively).

Fig. 3.2 presents the relative frequency of IAREs with some CDEP jobs identified in the 2006 census. Note that the frequency distributions exclude the three IAREs being studied. All three of the case studies are in the range of distribution where CDEP employment is relatively prominent. Hence the case studies are well chosen, in that if we are to expect the changes in the CDEP scheme to affect anywhere, it will be those three areas. 


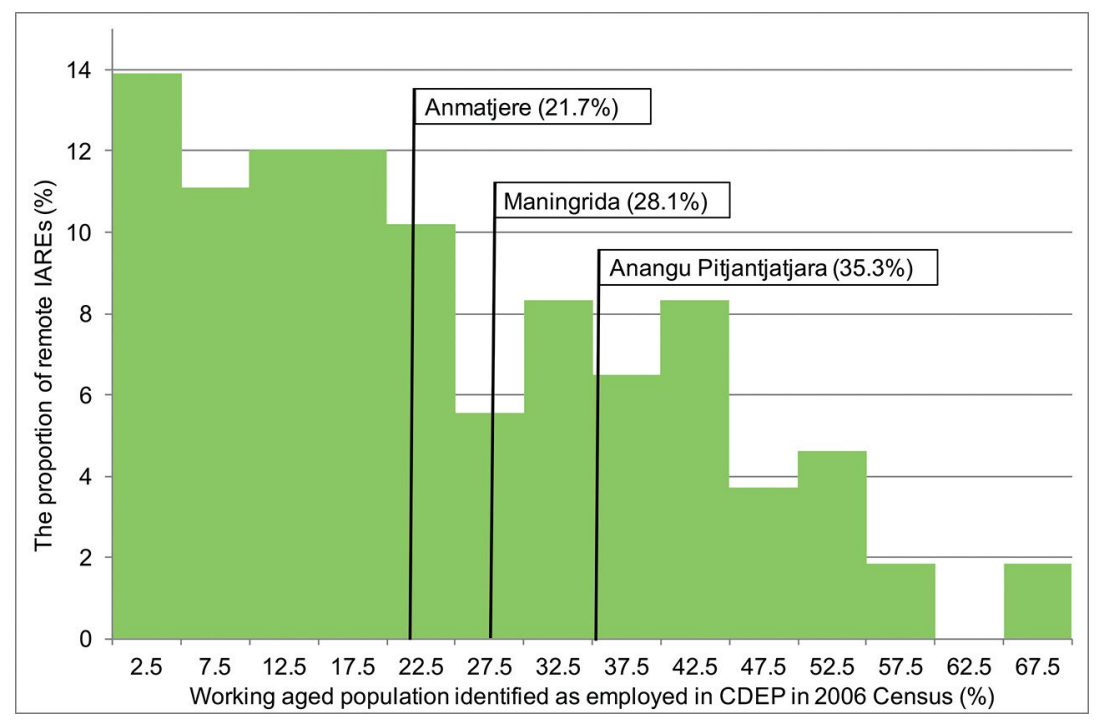

Fig. 3.2 The proportion of remote IAREs by per cent in CDEP employment in the 2006 census (\%)

Note: This figure excludes remote areas without any CDEP employment.

Source: Tablebuilder cross-tabulations from the 2006 census.

The reduction in the number of places available in the scheme nationwide manifested itself in Fig. 3.3, which reports the analogous relative frequency of incidence of CDEP employment among the working-age population in remote IAREs in 2011 (again excluding the three case studies). The first thing that is evident in Fig. 3.3 is that over two-thirds of remote IAREs have less than 10 per cent of the relevant populations working in the scheme in 2011. In 2006, only around one-quarter of IAREs had a similar prevalence of CDEP employment. Clearly there was a substantial contraction in CDEP employment in remote areas between 2006 and 2011. By the time of the 2011 census, the Anangu Pitjantjatjara and Anmatjere IAREs had around 10 per cent of the working-age population working in the scheme (9.8 per cent and 12.8 per cent respectively), according to the census. The CDEP scheme in Maningrida appeared to be relatively successful in retaining its places as almost one-fifth of the census working-age population still indicated they were working in the scheme in 2011. Accordingly, we might expect to see less impact of the CDEP reform, at least in terms of the effect of the loss of CDEP scheme jobs to 2011, in the Maningrida IARE. 


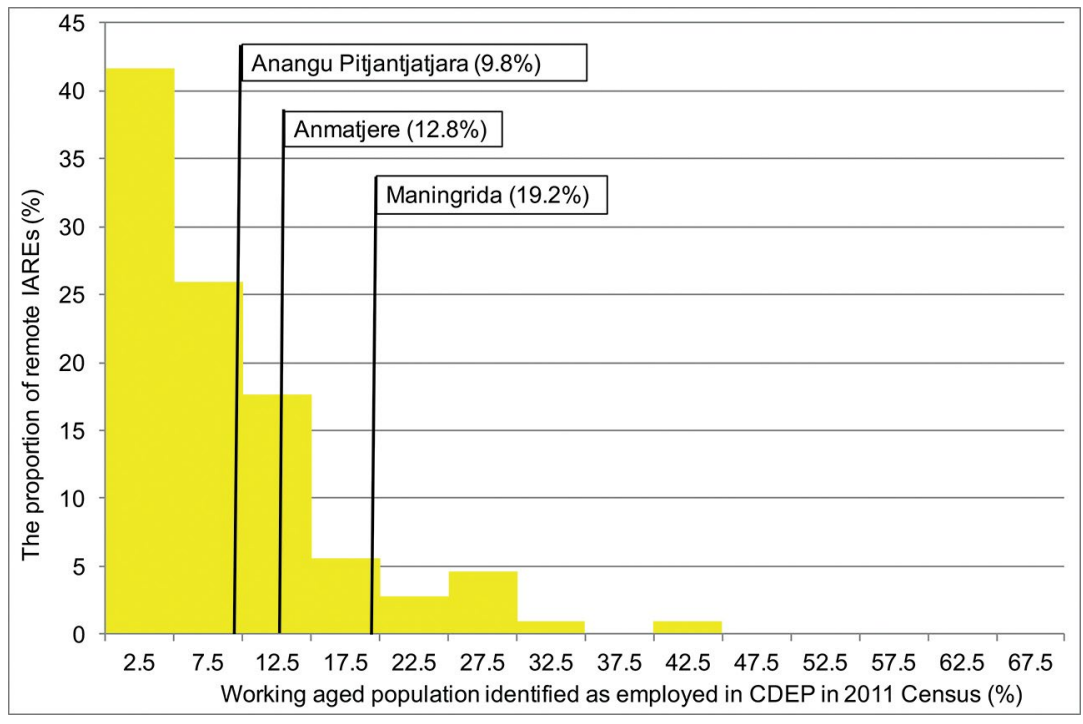

Fig. 3.3 The proportion of remote IAREs by per cent in CDEP employment in the 2011 census (\%)

Note: This figure excludes remote areas without any CDEP employment.

Source: Tablebuilder cross-tabulations from the 2011 census.

Figs 3.2 and 3.3 are based on census data on the level of CDEP scheme employment, which proved difficult to reconcile with the number of CDEP scheme participants in the administrative data provided in Table 3.4. The issue was especially pronounced in the 2011 census data for Anangu Pitjantjatjara areas, which may partially explain the apparently large fall in the $\mathrm{CDEP} /$ population ratio for that case study between 2006 and 2011. As documented above, the possible confusion about the treatment of CDEP in ABS collections around the time of the 2011 census means that the measured change in reported labour force status could be unreliable. Notwithstanding, the CDEP scheme is prominent in both censuses and the three remote case study areas will reflect the issues for CDEP intense areas.

As speculated above, CDEP may be more likely to be found in areas where there is little alternative employment. One of the major employers of Indigenous people in remote areas has been the mining sector. Hunter, Howlett and Gray (2014) demonstrated that areas with relatively high levels of mining were likely to have relatively positive outcomes for Indigenous people in both the labour and housing markets (although there was some evidence of housing stress among 
low-income renters). The level of mining activity in our case studies is negligible compared to other remote IAREs. Table 3.5 reports the percentage of areas with major mining investments in 2012 valued at over $\$ 50$ million. There appears to be a consistent tendency for the labour demand associated with mining to be higher in IAREs with less reliance on CDEP schemes. That is, there may have been an implicit trade-off between the number of jobs available outside the CDEP scheme and need to establish CDEP schemes in the first place. Certainly, the three remote case studies analysed in this volume have little access to major mines and hence the labour market alternatives to CDEP employment are likely to be rather limited. ${ }^{6}$

\section{Case study in the far south coast of NSW}

The far south coast case study is different from the remote case studies in several crucial ways. First, being located in 'outer regional' NSW it is more accessible to adjacent areas and towns. ${ }^{7}$ There is more scope for short-run mobility or even commuting to nearby areas with substantial labour markets (as long as one has access to affordable transport). Also, it may be easier to maintain social connections in the home community if a person migrates to a nearby town for work. The IARE geography used for the remote case study is not appropriate for setting the statistical context for this non-remote case study, in that there are two larger IAREs nearby and the data will be dominated by the large numbers of residents in the more populous areas. The number of jobs in the IAREs near Wallaga Lake is substantial with around 66 per cent of all working-age residents in the Bega Valley and Eurobodalla areas recorded as employed in the 2006 Census. The employment ratios declined by just over 5 percentage points in these areas. While the labour market is substantial in the far south coast, any changes in Indigenous employment outcomes must be viewed in the context of declines in the local labour market.

6 This observation is consistent with earlier evidence in Altman and Hunter (1996) that non-CDEP communities tended to have higher rates of private sector employment than CDEP communities. Table 3.5 shows that at least some of this employment differential is likely to be in the mining sector in more recent censuses. One caveat on the observation about mining employment is that Jordan (2011) identifies a mine that employed eight local people in the Anangu Pitjantjatjara region.

$7 \quad$ As classified by the ABS (2011c) remoteness classification. 
Rather than use an inadequate geographic level to analyse the local context, the following analysis uses the next level down in the ABS Indigenous geography, Indigenous Locations (abbreviated to ILOCs, as in ABS publications). While the population in ILOCs are more geographically homogenous, the number of residents tend to be very small and hence the capacity for detailed analysis is circumscribed.

The previous section compared the case study areas to all other remote areas by taking into account the level of CDEP employment identified in the 2006 census. However, it is not possible to take into account the level of CDEP employment in non-remote areas, because no such information is identified in the census. Accordingly, there is no natural comparator for the far south coast of NSW case study and hence this section focuses only on the Wallaga Lake ILOC in this region. The boundaries of the Wallaga Lake ILOC changed significantly between 2006 and 2011. In order to make valid geographic comparisons over time we again use population concordances provided by the ABS to ensure that all data effectively refer to the residents in the area defined by the 2006 Wallaga Lake ILOC boundaries.

Wallaga Lake community, unlike all the surrounding ILOCs, is a predominantly Indigenous community with relatively few nonIndigenous residents. Indeed, in 2011 there was no non-Indigenous person employed full-time in the community. Given the small populations involved, Table 3.6 focuses on basic count data and a few estimates of labour force status.

Table 3.6 Labour market outcomes for 15-64-year-olds by Indigenous status, Wallaga Lake, 2006 and 2011

\begin{tabular}{|l|r|r|r|r|}
\hline & & Indigenous & \multicolumn{2}{|r|}{ Non-Indigenous } \\
\cline { 2 - 5 } & 2006 & 2011 & 2006 & 2011 \\
\hline Counts aged 15-64 & 70 & 59 & 28 & 15 \\
\hline Employment/population ratios (\%) & 31.4 & 8.5 & 39.3 & 33.3 \\
\hline Unemployment/population ratios (\%) & 15.7 & 16.9 & 10.7 & 20.8 \\
\hline Labour force participation rates (\%) & 47.1 & 25.4 & 50.0 & 54.1 \\
\hline
\end{tabular}

Note: Apart from the counts, all statistics in this table are measured as a proportion of the working-age population counts. The labour force participation rate is equal to the sum of the employment/population ratio and the unemployment/population ratios. The reference to labour force participation rates, but not employment and unemployment rates, is intentional. In the standard labour economics literature, the terms employment and unemployment rates are usually expressed as a proportion of the labour force and not as a proportion of the working-age population. The unemployment/population ratios are based on relatively 
small cell sizes, that may be affected by the ABS practice of confidentialising small area data, especially the non-Indigenous unemployment data in Wallaga Lake. This data should be treated with caution.

Source: ABS Tablebuilder for the 2006 and 2011 censuses.

The first thing evident in Table 3.6 is that Wallaga Lake was a small community that appeared to become smaller, at least in terms of the working-age population. Population level data often adjust for the undercount or the propensity to not count certain groups in the population. Indigenous people have historically been identified as a group with a high undercount, but population adjustments to correct for this tendency are not available for ILOC or even IARE levels, hence it is impossible to calculate the local Estimated Residential Population. Unless the undercount rate increased dramatically over time, the Wallaga Lake population fell substantially between 2006 and $2011 .{ }^{8}$ The population decline is most marked in the non-Indigenous census counts, falling by almost half in this period (i.e. from 28 to 15).

One possible reason for population decline is an economic shock such as the closure of the local CDEP scheme. Another explanation might be the rise of community conflict in the community that encouraged some residents to leave. The census estimates indicate that the employment rate collapsed after 2006, and by 2011 only 8.5 per cent of the Indigenous working-age population were employed. The employment ratio for the non-Indigenous population appeared to hold up somewhat better, but the population leakage means that the effective number of employed halved in that five-year period.

One possible response to the loss of CDEP jobs among Indigenous residents who remained in Wallaga Lake was to leave the labour force altogether. The labour force participation rate of the workingage Indigenous population was cut almost in half, from 47 per cent to 25 per cent. The Indigenous unemployment ratios have stayed largely unchanged with around one in six of the working-age population being unemployed in both 2006 and 2011. Wallaga Lake was a disadvantaged community in 2006 and remained so in 2011. While it is not reported in Table 3.6 to save space, all households in

8 It is also possible that the local population fluctuates naturally in coastal communities in the short term, but the census data is consistent with a substantial population decline in this period. 
the community (both Indigenous and non-Indigenous households) were in the lowest category of (equivalised) household income in both census years.

In summary, like the remote case studies, Wallaga Lake community was heavily dependent on CDEP for providing jobs. All the case studies in this volume will provide substantial insights into the significant loss of CDEP employment on the local communities.

\section{Concluding comments}

Overall, the above evidence indicates that the remote case studies are broadly representative of communities with substantial concentrations of CDEP employment. Furthermore, there is sufficient CDEP engagement and changes in the numbers of CDEP participants over time (after taking into account population growth rates) to reasonably expect some socioeconomic change resulting from the changes in the rules and organisation of the schemes. In a sense, the above analysis provides a rationale for and a validation of the choice of organisations and areas covered in the case studies. The administrative data also illustrate the dynamic nature of the organisations that managed CDEP and provide an indication of the challenges that are faced in comparing organisations whose nature and scope changed at regular intervals.

One might expect the far south coast of NSW case study to be more affected by the changes to CDEP than the remote case studies in the intercensal period, in that CDEP schemes retained a significant presence in the latter but disappeared completely in the former. Outcomes there may provide some indication of what might happen in remote areas now those schemes have been closed down completely.

CDEP or similar programs can have substantial effects of boosting the local economy. Mouda (2001) argued that it was essential for CDEP organisations to exploit any economies of scale so that their activities could contribute to the local economy (also see Nalliah 2001). While the rationalisation and amalgamations of CDEP organisations that took place around 2006-07 make it difficult to analyse administrative data, it would be a mistake to completely ignore the potentially lower costs associated with the economies of scale of larger organisations, and associated trade-offs, if those savings were to be realised. However, 
consideration of such matters is left to the case studies whose indepth analysis is better suited to providing the context necessary to understand the trade-offs involved than the statistical context presented in this chapter.

\section{References}

ABS (Australian Bureau of Statistics) (201 la). Labour force characteristics of Aboriginal and Torres Strait Islander Australians, estimates from the Labour Force Survey, 2010, cat. no. 6287.0, ABS, Canberra.

ABS (Australian Bureau of Statistics) (2011b). Census dictionary, Australia, 2011, cat. no. 2901.0, ABS, Canberra.

ABS (Australian Bureau of Statistics) (2011c). Australian Standard Geographical Classification, cat. no. 1216.0, ABS, Canberra.

ABS (Australian Bureau of Statistics) (2012a). Labour force characteristics of Aboriginal and Torres Strait Islander Australians, estimates from the Labour Force Survey, 2011, cat. no. 6287.0, ABS, Canberra.

ABS (Australian Bureau of Statistics) (2012b). 2011 Census of population and housing - details of undercount, Australia, cat. no. 2940.0, ABS, Canberra.

ABS (Australian Bureau of Statistics) (2013a). Australian social trends, Nov 2013, cat. no. 4102.0, ABS, Canberra.

ABS (Australian Bureau of Statistics) (2013b). Labour force, Australia, Jun 2013, cat. no. 6202.0, ABS, Canberra.

ABS (Australian Bureau of Statistics) (2013c). Information paper: Australian Census longitudinal dataset, methodology and quality assessment, 2006-2011, cat. no. 2080.5, ABS, Canberra.

Altman JC, Gray MC \& Sanders W (2000). Indigenous Australians working for welfare: what difference does it make? Australian Economic Review 33 (4), 355-62. 
Altman JC \& Hunter B (1996). The comparative economic status of $C D E P$ and non-CDEP community residents in the Northern Territory in 1991, CAEPR Discussion Paper No. 107, Centre for Aboriginal Economic Policy Research, The Australian National University, Canberra.

Borland J \& Tseng Y (2011). Does 'Work for the Dole' work?: an Australian perspective on work experience programmes. Applied Economics 43 (28): 4353-68, DOI: 10.1080/00036846.2010.491457.

Forrest A (2014). The Forrest review: creating parity, Commonwealth of Australia, Canberra.

Gray M, Howlett M \& Hunter B (2014). Labour market outcomes for Indigenous Australians. The Economic and Labour Relations review, 25(3): 497-517 DOI: 10.1177/1035304614545943.

Gray M \& Hunter B (2005). The labour market dynamics of Indigenous Australians. Journal of Sociology, 41(4): 389-408.

Gray M, Hunter B \& Howlett M (2013). Indigenous employment: a story of continuing growth. Topical Issue 2/2013, Centre for Aboriginal Economic Policy Research, The Australian National University, Canberra.

Hunter B (2009). A half-hearted defence of CDEP scheme. Family Matters 81: 43-54. aifs.gov.au/publications/family-matters/ issue-81/half-hearted-defence-cdep-scheme.

Hunter B \& Daly A (2013). The labour supply of Indigenous Australian females: the effects of fertility and interactions with the justice system. Journal of Population Research, 30(1): 1-18.

Hunter B \& Gray M (2013). Continuity and change in the CDEP scheme. Australian Journal of Social Issues, 48(1): 35-56.

Hunter B, Gray M \& Jones R (2000). An analysis of data from the longitudinal survey of ATSI job seekers, topic 1: labour market participation patterns and pathways to employment, Report to the Department of Employment, Workplace Relations and Small Business, Centre for Aboriginal Economic Policy Research, The Australian National University, Canberra (archived at pandora. nla.gov.au/tep/39721). 
Hunter B, Howlett M \& Gray M (2014). The mining boom and Indigenous socio-economic status, Working Paper 93, Centre for Aboriginal Economic Policy Research, The Australian National University, Canberra.

Jordan K (2011). Work, welfare and CDEP on the Anangu Pitjantjatjara Yankunytjatjara Lands: first stage assessment, Working Paper No. 78, Centre for Aboriginal Economic Policy Research, The Australian National University, Canberra.

Martin D (2001). Community development in the context of welfare dependence. In Morphy F \& Sanders W (eds), The Indgineous Welfare Economy and the CDEP Scheme, CAEPR Research Monograph No. 20, ANU E Press, Canberra.

Mouda R (2001). A part of the local economy: Junjuwa Community/ Bunuba Inc., Western Australia. In Morphy F \& Sanders W (eds), The Indgineous Welfare Economy and the CDEP Scheme, CAEPR Research Monograph No. 20, ANU E Press, Canberra.

Nalliah S (2001). Adequate funding as a question of equity: Lake Tyers Aboriginal Trust CDEP, Victoria. In Morphy F \& Sanders W (eds), The Indgineous Welfare Economy and the CDEP Scheme, CAEPR Research Monograph No. 20, ANU E Press, Canberra.

Sanders W (2012). Coombs' bastard child: the troubled life of the CDEP scheme. Australian Journal of Public Administration, 71 (4): 371-9. 
This text is taken from Better Than Welfare?: Work and livelihoods for Indigenous Australians after CDEP, edited Kirrily Jordan, published 2016 by ANU Press, The Australian National University, Canberra, Australia. 